\title{
FIPA İngiliz Açık Artırma Protokolünün Rol Tabanlı Bir Çoklu Etmen Çerçevesi ile Gerçekleştirilmesi
}

\author{
Ali Murat Tiryaki ${ }^{1 *}$, Varol Güven ${ }^{2}$ \\ 1* Çanakkale Onsekiz Mart Üniversitesi, Mühendislik Fakültesi, Bilgisayar Mühendisliği Bölümü, Çanakkale, Türkiye (ORCID: 0000-0001-8224-6319), \\ tiryaki@ comu.edu.tr \\ ${ }^{2}$ Çanakkale Onsekiz Mart Üniversitesi, Mühendislik Fakültesi, Bilgisayar Mühendisliği Bölümü, Çanakkale, Türkiye (ORCID: 0000-0003-2246-3463), \\ vguven@comu.edu.tr
}

(2nd International Conference on Access to Recent Advances in Engineering and Digitalization (ARACONF)-10-12 March 2021)

(DOI: 10.31590/ejosat.902173)

ATIF/REFERENCE: Tiryaki, A.M. \& Güven, V. (2021). XFIPA İngiliz Açık Artırma Protokolünün Rol Tabanlı Bir Çoklu Etmen Çerçevesi ile Gerçekleştirilmesi. Avrupa Bilim ve Teknoloji Dergisi, (24), 392-397.

$\ddot{\mathbf{O z}}$

Etmenler özerk ve karmaşık yazılım birimleridir. Etmenlerin önemli karakteristiklerinden birisi sosyalliktir. Etmenler genellikle kendi hedefleri doğrultusunda içinde bulundukları çoklu etmen sistemde bulunan diğer etmenler ile etkileşimli bir şekilde çalışarak bu hedeflere ulaşmaya çalışıllar. Etmenlerin aynı platformda veya başka platformlarda bulunan diğer etmenlerle iletişim kurabilmesi ancak ve ancak etmenler arası haberleşmenin belirli iletişim ve etkileşim standartlarına dayandırılmasıyla gerçekleşebilir. Standartların tanımlanması etmen teknolojisinin endüstri tarafından kabul edilebilirliğini arttırmaktadır. Bu çalışmada, FIPA kuruluşu tarafından tanımlanmış olan "İngiliz Açık Artırma" isimli etkileşim protokolü SEAGENT çerçevesi tarafindan sunulan rol tabanlı geliştirim ortamı ile gerçekleștirilmiştir. Çalışma sonucunda, FIPA İngiliz Açık artırma protokolünde bulunan etmen rolleri ve bu rollerin hedeflerini gerçekleştiren planlar elde edilmiştir. Geliştirilen bu genel planlar SEAGENT çerçevesi kullanılarak geliştirilecek çoklu etmen sistem uygulamalarında kolaylıkla yeniden kullanılabilir.

Anahtar Kelimeler: Yazılım etmenleri, Çoklu etmen sistemleri, Etmen standartları, etkileşim protokolleri.

\section{Implementation of the FIPA English Auction Protocol with a Role- Based Multi Agent Framework}

\begin{abstract}
Agents are autonomous and complex software units. One of the major characteristics of agents is sociality. In general, agents do not work single to achieve their objectives. They try to achieve own objectives by working collaboratively with other agents situated in same multi agent system(s). Collaboration among agents situated in same or different agent platform(s) is realizable if and only if correspondence among agents is based on specific communication and interaction standards. Definition of standards increase acceptability of agent technology by industry. In this study, the interaction protocol named as "English Auction" which has been specified by FIPA was implemented by using the role-based development environment provided by SEAGENT framework. As a conclusion of the study, the agent roles and the agent plans that achieve the goals of these roles in the FIPA English Auction Protocol were obtained. These generic plans can be simply reused in other multi agent system applications developed using SEAGENT framework.
\end{abstract}

Keywords: Software agents, Multi agent systems, Agent standarts, Interaction protocols.

*Sorumlu Yazar: tiryaki@ comu.edu.tr 


\section{Giriş}

Son y1llardaki önemli araştırma alanlarından biri olan anlamsal veb (semantic web) $[1,2]$ verilerin anlamsal bir şekilde tanımlanmasını sağlayarak bilgisayarların günümüz vebinde insanlar tarafindan yapılabilen yorumlamaları yapabilmesini hedeflemektedir. Buradaki anlamsallıktan kasit verinin yazılımlar tarafından anlaşılabilir ve bu sayede otomatik işlenebilir bir formatta tanımlanması ve tutulmasıdır.

Anlamsal veb vizyonu iki temel teknoloji üzerine kuruludur. Bunlardan birincisi, verilerin anlamsal bir formatta tutulmasını sağlayan, mantık tabanlı ontoloji dilleridir. İkincisi ise anlamsal formatta tutulan verinin üzerinde çalışarak veriyi yorumlayacak ve işleyecek özerk ve akıllı yazılımlar olan etmenlerdir (agents) [3]. Vebdeki verilerin bilgisayarlar tarafindan otomatik olarak yorumlanabilmesi ve işletilebilmesi hedefi ancak ve ancak bu iki teknolojinin birlikte kullanılmasıyla başarılabilir.

Yazılım etmenleri (software agents) [4][5], anlamsal vebde ontolojiler üzerinde çıkarsama yapabilecek yapay zeka teknikleri ile oluşturulmuş özerk ve sosyal yazılım sistemleridir. Bilişsel (cognitive) yeteneklerinin yanında çevresinde olup biteni algılama (perception), özerklik (autonomy), öğrenme (learning) ve çıkarsama (reasoning) yapma gibi yeteneklere de sahiptir. Vebde kullanıcıları için beklenen görevleri yerine getirmek üzere sürekli olarak ortamı takip ederek ortamdaki değişiklikler karşısında tepki verebilme, sahip oldukları bilgi tabanlarını güncelleyebilme, kullanıcılarına veya ortamdaki diğer etmenlere haber verebilme gibi işlemleri kullanıcının tetiklemesine gerek duymadan kendi kendine karar verebilme yeteneğine sahiptirler. Etmen bu kararları verirken ortamın ve sahip olduğu bilgi tabanının güncel durumunu ve kendisine daha önceden atanmış olan hedefleri değerlendirirler [6].

Veb gibi etkileşime açık ortamlarda etmenler genellikle hedeflerini tek başlarına yerine getiremezler. Ortak hedeflere sahip olan etmenler bir araya getirilerek Çok Etmenli Sistem ÇES (Multi Agent System - MAS) adı verilen federal yapıları oluştururlar [7]. ÇES'ler çalışma zamanında yeni etmenlerin eklenebildiği veya varolan etmenlerin ayrılabildiği açık ve dinamik sistemlerdir. Diğer yandan, ÇES içerisindeki her etmen kendi bilgi tabanını ve hedeflerini kendi başına yönetme yetkisine sahiptir. Her etmen bilgi tabanını oluşturmak ve yönetmek için farklı teknolojiler kullanabilir. Bu yüzden dolayı ÇES'ler heterojen dağıtık sistemlerin bir türü olarak sinıflandırılmaktadır [8].

Vebin global yapısı düşünüldüğünde, aynı ÇES içerisinde yer alan heterojen etmenlerin, hatta farklı ÇES'lerin aralarında etkileşimli çalışabilmelerinin sağlanması anlamsal veb vizyonundaki hedeflerin yerine getirilmesi için en önemli konular arasında yer almaktadır. Bu dinamik ve heterojen ortamda etmelerin birlikte çalışabilmesi ancak ÇES mimarisinin, etmenler arası haberleşmenin ve etkileşimin belirli standartlara ve önceden tanımlanmış protokollere dayandırılması ile sağlanabilir [9]. Bu yüzden, etmen sistemler için böyle standartların tanımlanması ÇES geliştirimi alanı içerisinde önerilmiş konulardan bir tanesidir.

Günümüze kadar çeşitli araştırma grupları ve kurumlar, etmen sistemler için standart tanımlama üzerine çalışmaktadırlar. Bunlar arasında Akıllı Fiziksel Etmenler Kurumu - AFEK (The Foundation for Intelligent Pysical Agents - FIPA) [10] isimli kurumun standartları diğerlerinden önce çıkmış ve etmenler e-ISSN: 2148-2683 üzerine çalışan araştırmacılar tarafından geniş çapta kabul görmüştür. FIPA, çok etmenli sistemler arasındaki birlikte çalışabilirliği (interoperability) en üst düzeye çıkartmak için evrensel standartlar ortaya koymak amacı ile kurulan, kar amacı gütmeyen bir topluluktur. Kuruluşun isminde "fiziksel" kelimesinin geçmesinin nedeni, kuruluşun yalnız yazılım tabanlı değil aynı zamanda donanım tabanlı etmenlerle de ilgilenmeleridir. FIPA günümüze kadar etmen sistemler için W3C tarafından kabul edilmiş pek çok standart tanımlamıştır.

Jade [11], Retsina [12], DECAF [13] ve SEAGENT [14] gibi birçok ÇES çerçevesi FIPA standartları üzerine kuruludur. ÇES çerçevelerinin FIPA uyumlu olması bu çerçevelerin akademik ve ticari ortamda kabul edilebilirliğini önemli ölçüde arttırmaktadır. FIPA standartlarının bu çerçeveler ile gerçekleştirimi üzerine çalışmalar FIPA standartlarının ÇES tasarımı sırasında nasıl kullanılacağını belirterek bu standartların somutlaştırılmasını sağlamaktadırlar.

FIPA, ÇES'ler içerisindeki etmenler arası etkileşimleri standart hale getirmek adına istek, pazarlık ve açık artırma gibi çeşitli etkileşim protokolleri tanımlamıştır. Her etkileşim protokolü iki veya daha fazla etmenin ortak bir hedefi başarmak üzere birlikte çalışması sürecini ve bu süreç boyunca etmenler arası gidip gelen mesajları tanımlamaktadır.

$\mathrm{Bu}$ çalışmada, FIPA tarafından tanımlanmış olan İngiliz Açık Artırma (English Auction) etkileşim protokolü [6] SEAGENT ÇES geliştirim çerçevesi ile gerçekleştirilmiştir. Bir açık artırma sürecinde bir satıcı ve birden fazla alıcı etmen yer almaktadır. Satıcı etmen belirli bir ürünü veya servisi satmak veya kiralamak üzere açık artırmaya sunar. Alıcı etmenler kendilerine atanan sorumluluk ve yetkiler dâhilinde kullanıcılarına avantaj sağlayacak şekilde fiyatı artırır veya gerekli gördüklerinde açık artırmadan çekilirler. En son, en yüksek fiyatı öneren alıcı etmen satıcı etmen ile anlaşarak ürünülservisi alır veya kiralar. FIPA İngiliz Açık Artırma protokolü bu süreç içerisinde etmenler arası gidip gelen mesajların içeriğini ve sırasını tanımlamıştır. Protokoldeki alıcı ve satıcı rolleri için bu mesajları üreten ve gelen mesajlar karşısında kararlar veren etmen planları gerçekleştirilmiştir. Geliştirilmiş olan bu etmen planları SEAGENT çerçevesi kullanılarak geliştirilecek ÇES uygulamaları içerisinde açık artırma gerektiği yerlerde yeniden kullanılabilecek halde tasarlanmış ve SEAGENT plan kütüphanesine eklenmiştir.

Bildirinin bir sonraki bölümünde, çalışmanın altyapısını oluşturan İngiliz Açık Artırma protokolü tanıtılmaktadır. Üçüncü bölümde SEAGENT platformunun genel karakteristikleri ve geliștirim ortamı incelenmektedir. Dördüncü bölümde FIPA İngiliz Açık Artırma Protokolü'nün SEAGENT çerçevesinin sunduğu geliştirim ortamında gerçekleştirimi ile ilgili detaylar sunulmaktadır. Son bölümde ise çalışma ile ilgili tartışma ve sonuç yer almaktadır.

\section{FIPA İngiliz Açık Artırma Protokolü}

FIPA İngiliz Açık Artırma Etkileşim Protokolü [14] bir ürünün satıcısı ile alıcılar arasında açık artırma ile ürünün fiyatının belirlenmesi için tanımlanmıştır. Protokolün önerdiği süreçte, satıcı pazarın talep ettiği değerin altında bir fiyat önererek ve belirli durumlarda bu fiyatı arttırarak bir pazar fiyatı bulmaya çalışır. Fiyatın her açıklanışından sonra, satıcı teklif edilen fiyatı ödemek isteyen herhangi bir alıcının olup olmadığını görmek istemektedir. Herhangi bir alıcı bu fiyatı 
kabul ettiğini bildirdikten sonra, satıcı fiyatı tekrar arttırarak, bunu katılan tüm alıcılara bildirir. Artırılan fiyatı ödemeyi kabul eden bir alıcı olmadığında ise pazarlık sona ermektedir. Pazarlık sonunda ödenmesi kabul edilen en son fiyat pazarın talep ettiği değerin altında ise ticari bir işlem gerçekleşemez. Eğer alıcı talep edilen fiyatın üstünde bir değer ödemeyi kabul etmiş ise ticari bir işlem gerçekleşmektedir.

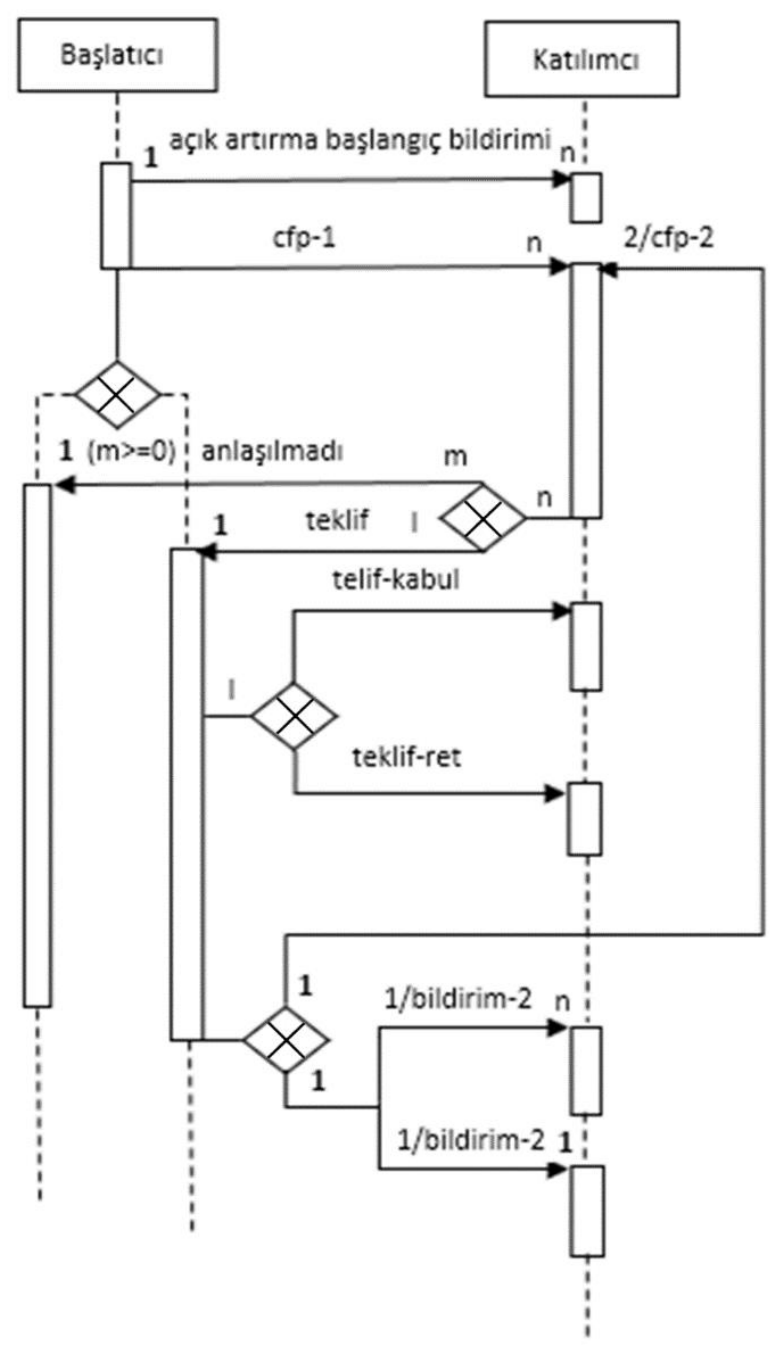

Şekil 1. FIPA İngiliz Açık Artırma Protokolü

Protokolün temel sürecini gösteren etkileşim diyagramı Şekil-1'de sunulmuştur. Kolay anlaşılabilirlik bakımından bu diyagramda katılımcı sayısı bir olarak gösterilmiştir.

Şekilde pazarlığı başlatan taraf tüm katılımcılarına öncelikle pazarlığın başladığını bildiren bir bilgi (inform) mesajı göndermektedir. FIPA İngiliz Açık Artırma Etkileşim Protokolü'nde alıcı ya da satıcı taraflarından birisinin sayısının bir tane olması zorunlu iken, diğer tarafın sayısının birden fazla olabildiği görülmektedir. Gönderilen bilgi mesajının arkasından bir Teklif İçin Çağrı - TİÇ (Call For Proposal - CFP) mesajı gönderilmektedir.

Katılımcı, bilgi ve TİÇ mesajlarını aldıktan sonra kendi iç durumunu gözden geçirerek, öneri beklemekte olan tarafa bir cevap hazırlamaktadır. Bu cevap, alınan mesajın anlaşılmadığını bildiren bir mesaj (not-understood) veya bir teklif (propose) mesajı olabilmektedir.
Teklif mesajının içeriğinde ise gelen TİÇ mesajının içeriği değerlendirilerek hazırlanmış yeni bir teklif bulunmaktadır. Pazarlığı başlatan taraf katılımcılardan gelen her mesaj değerlendirdikten sonra, teklif gönderen katılımcılara tekliflerini kabul ettiğini bildiren (accept-proposal) ya da reddettiğini bildiren (reject-proposal) mesajı gönderir. Pazarlığı başlatan taraf, gelen teklif mesajlarının sayısına göre pazarlığa devam edilip edilmeyeceğine karar verir.

Eğer pazarlığa devam edilecekse katılımcılara yeni bir TİÇ mesajı gönderilir. Pazarlık sona ermişse, tüm katılımcılara pazarlığın bittiğini bildiren bir bilgi (inform) mesajı gönderilir. Kazanan katılımciya ise ayrıca bir istek (request) mesajı gönderilir.

\section{Seagent Çoklu Etmen Çerçevesi}

SEAGENT [15] anlamsal veb tabanlı çok etmenli sistemlerin geliştirilmesini sağlayan bir etmen yazılımı çerçevesi ve platformudur. SEAGENT'in iletişim ve plan çalıştırma altyapıs1, DECAF ve RETSINA gibi mevcut diğer etmen geliştirme çerçeveleri ile benzerlikler göstermektedir. Ancak [16]'da belirtildiği gibi SEAGENT, anlamsal veb tabanlı çok etmenli sistemi geliştirmeyi desteklemek ve kolaylaştırmak için diğer etmen geliştirme çerçevelerinin sahip olmadığı ve aşağıda listelenen özelliklere sahiptir.

- SEAGENT, bir etmenin iç mimarisinde Ontoloji Veb Dili'ne dayalı bilgi depolarını kullanmasına imkân vermektedir.

- SEAGENT'a dayalı olarak geliştirilen etmen dizin servisleri OWL tabanlı ontolojiler kullanılarak hazırlanmış etmen yetenek ilanlarını depolayabilirler ve platform etmenlerinin aradıkları etmen yeteneklerinden anlamsal olarak en uygunlarının geliştirilmesini sağlayan anlamsal eşleme motorlarına sahiptirler.

- SEAGENT bünyesinde FIPA-RDF'e [17] dayalı SEAGENT İçerik Dili adı verilen bir içerik dili, etmen mesaj iletişimlerinde anlamsal içeriğin transfer edilmesi için tanımlanmıştır.

- SEAGENT, FIPA uyumlu diğer etmen çerçevelerinin sunduğu servislere ek olarak "Ontoloji Yönetim Servisi" adi verilen yeni bir etmen servisi tanıtmaktadır. $\mathrm{Bu}$ servisin en önemli özelliği bir etmen platformuna ait ontolojiler ile harici ontolojiler arasındaki eşlemeyi tanımlamasıdır. Böylelikle bu eşlemelere dayalı olarak etmenler için bir ontoloji dönüşüm servisi sunulmaktadir.

- SEAGENT anlamsal veb servislerinin etmenler tarafindan keşfini ve dinamik olarak çalıştırılmasını desteklemektedir. SEAGENT bünyesinde anlamsal servis keşfi için ayrı bir platform servisi tanımlanmıştır. Keşfedilen servislerin dinamik çağrılması için de SEAGENT plan kütüphanesi hazır ve yeniden kullanılabilir etmen davranışlarını içermektedir.

SEAGENT çok etmenli geliştirme çerçevesi iki ortamın birleşiminden oluşmaktadır: SEAGENT geliştiricilerine görsel geliştirim ortamı sağlayan SEAGENT Geliştirme Ortamı - SGO ve altyapı elemanlarını içeren SEAGENT Çalıştırma Ortamı SÇO [18]

SEAGENT Çok Etmenli Platformu'nda kolay yazılım geliştirmek için SEAGENT Geliștirme Ortamı - SGO ortaya çıkarılmıştır. $\mathrm{Bu}$ ortam kullanılarak yazılımcı geliştirmekte olduğu yazılımın genel çatısını oluşturabilmekte ve bu sayede 
yazılımcı yazılım etmeni geliştirmenin zorluğundan kurtarılmaya çalışılmaktadır.

SGO, çok etmenli sistemleri geliştirmek isteyen geliştiriciler tarafından kullanılan bir ortamdır ve genel olarak üç geliştirim aracından oluşur. Bu araçlar: Hiyerarşik Görev Ağ1 Düzenleyici, Rol Gezgini ve Hedef Düzenleyici'dir. Plan Düzenleyici; etmenlerin davranışlarını ve eylemlerini, yani kısacası planlarını görsel olarak gösterebilen ve aralarında ilişki kurulmasına olanak sağlayan bir yapı sunar. Rol gezgini, etmenlere ait olan davranışların yeniden kullanılabilirliğini sağlar. Hedef düzenleyici ise, organizasyonların ve rollerin hedeflerinin geliştirilmesine olanak sağlar.

\section{Protokolün Gerçekleştirimi}

SEAGENT etmen çerçevesi, etmenlerin birbirleriyle iletişim halindeyken gönderdikleri bilgiler aynı zaman biriminde tek bir çıkışa izin vermektedir. Etmenden gelen mesaja karşı bir çıkış bilgisi hazırlanır ve gönderilir. Bundan dolayı karmaşık etkileşim protokollerinin doğrudan gerçekleştirilmesini desteklememektedir.

İngiliz açık artırma etkileşim protokolünde satıcı tarafından istenen teklif isteklerine alıcı etmenlerin verecekleri cevapların iş süreçlerini gerçekleştirebilmek için rol kavramından yararlanılmıştır. Oluşturulan hedef işler yani etmenlerin yapması gereken işler bu etmenlere kullanılmak üzere bağlanmıştır. Aynı hedef işleri farklı etmen birimlerini kullanabilmektedir. Örneğin alıcı etmenlerin tekliflerini gönderecekleri planların bulunduğu teklif gönderme rolü alıcı etmenlere atanmıştır. Sadece her etmenin kendi bilgi tabanlarında tuttukları bilgiler farklıdır. Kendi bilgi tabanlarıyla bu hedef işleri birleştirilerek yapması gereken iş tamamlanır.

FIPA İngiliz Açık Artırma Etkileşim Protokolü SEAGENT üzerinde gerçekleştirilirken rol geliştirim alt yapısından yararlanılmıştır. Rol geliştirim sürecinde etmenlere yapacakları işle ilgili bir rol atanmış ve bu rolün gerçekleştireceği işler belirlenmiştir. $\mathrm{Bu}$ işler, etmenin yapması gereken hareketlerin tanımlandığı Sıragdüzensel Görev Ağı - SGA (Hierarchical Task Network - HTN) [19] alt yapısı kullanılarak belirlenmiştir. Rol yapısı oluşturularak etmenlerin karmaşı görevleri yapmaları sağlanmıştır. Protokolün içerdiği roller ve bu rollere bağlanan hedefler arasındaki ilişkileri gösteren organizasyon diyagramı Şekil 2'de gösterilmektedir.

SGA ihtiyaç duyulan yeniden kullanılabilir etmen planlarını ve ilgili davranış kütüphanelerini içermektedir. Yeniden kullanılabilir etmen planları bir etmenin niyetlerine uygun olarak işletilen görevlerinin birleşiminden oluşmaktadır. Etmen ortamdan elde ettiği algılara tepki olarak bu planların birini ya da birkaçını uygulamaya geçirir. Oluşturulan SGA planları başka etmenler tarafindan da tekrar kullanılabilir.

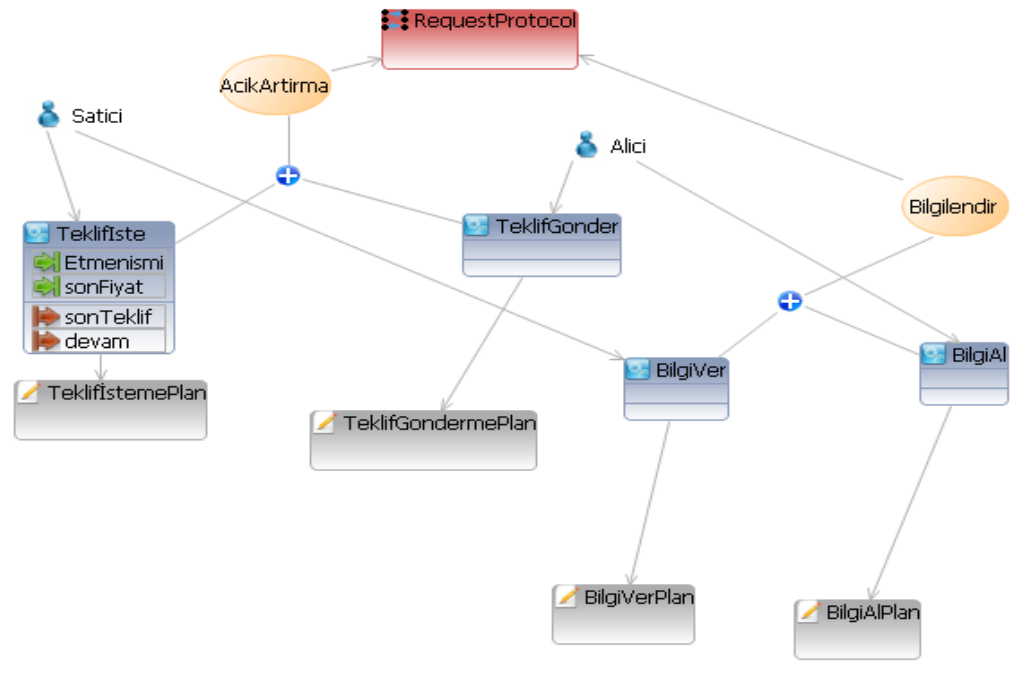

Şekil 2. Ingiliz Açık Artırma için Organizasyon Diyagramı

\section{1. İngiliz Açık Artırma Etmen Planları}

SEAGENT platformunda etmen planları SGA paradigması kullanılarak geliştirilmektedir. SGA planları içerisinde etmenlerin yapacakları görevler geliştirici tarafından kodlanarak iş süreçleri gerçekleştirilir. Etmenlerin yapacakları işler davranış olarak ele alınır ve bu davranışlar daha küçük iş parçacıklarına ayrılır. Bu şekilde karmaşık işler daha basit görevlere ayrılarak gerçekleştirilir. Aynı zamanda modülerliği artırdığı gibi kodların da yeniden kullanılabilir hale gelmesi sağlanmış olur. Bu çalışmada görevler gerçekleştirilirken aynı yapı kullanılmıştır.

FIPA İngiliz Açık Artırma Protokolü'nün SEAGENT ile geliştirilmesi için bu protokolde yer alan alıcı ve satıcı etmenlere ait planlar SEGANT çerçevesi kullanılarak geliştirilecek ÇES uygulamalarında yeniden kullanılabilecek genel (generic) plan yapıları olarak oluşturulmuş ve bu planlar içerisindeki eylemler
Java dili kullanılarak gerçekleştirilmiştir. $\mathrm{Bu}$ bölümde, gerçekleştirilmiş olan bu genel planlar anlatılmaktadır.

Geliştirim sürecinde öncelikle bir satıcı etmen oluşturulmuştur. Satıcı etmenin görevi kendisine bağlanmıştır. Satıcı etmen kendi bilgi tabanını kullanarak ortamda bulunan alıcı etmelere bir ürünü satışa çıkarır. Bunu yaparken Teklifíste hedefini çalıştırır. Teklifíste hedefi, hedef etmen isimlerini, bu etmenlerden gelen teklifleri, bu gelen tekliflerden en büyüğünü ve açık artırmanın devam edip etmemesini tutan alanları barındırır. Bu planlamada satıcı etmenin bildirdiği fiyata gelen tekliflerden en büyük olan seçilmekte ve bu fiyat tekrardan alıcı etmenlere gönderilmektedir. $\mathrm{Bu}$ süreç satıldı bilgisi yayınlana kadar devam etmektedir. Satıldı bilgisi alıc1 etmene satıc1 etmen tarafından gönderilir.

Şekil 3'te satıcı etmenin plan bilgisi yer almaktadır. Önceki çalışmalar bölümünde SGA yapısını anlatırken verilen 
davranışların yani karmaşık görevlerin buradaki karşılığı BHTeklifİstemePlan karmaşık görevidir. Bu karmaşık görev daha küçük parçalara ayrılarak çalışabilir kod parçalarının bulunduğu eylemlere dönüştürülmüştür. $\mathrm{Bu}$ eylemlerde TeklifIstemePlanACSendrequest sınıfı gibi direkt çalıştırılabilir kod parçalarının olduğu sınıflardır. $\mathrm{Bu}$ sınıflar sayesinde karmaşık görevler parçalanarak iş yükleri dağıtılmıştır.

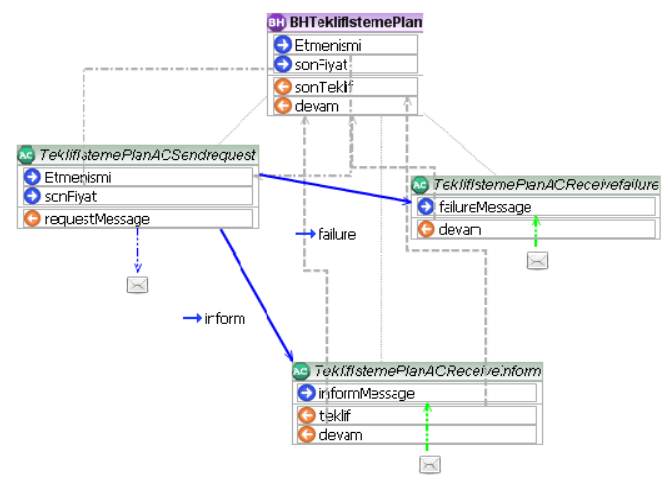

Şekil 3. Satıcı Etmen Teklif İsteme Planı.

BHTeklifistemePlanı kendisine gelen teklifleri etmen isimleriyle birlikte değerlendirmekte ve bu değerlendirmeyi TeklifIstemePlanACSendrequest sinifinın requestMessage fonksiyonu bütün alıcı etmenlerden istekte bulunmaktadır. $\mathrm{Bu}$ istek sonucunda gelen bilgiler sinif tarafindan değerlendirilmektedir. TeklifIstemePlanACReceiveinform sinıfi kendisine gelen fiyat bilgisini satıc1 etmenin veri tabanında bulunan fiyat bilgisine atamaktadır. Eğer herhangi bir alıcı etmen teklif göndermede başarısız olursa bu da TeklifIstemePlanACReceivefailure fonksiyonu ile bilgilendirilmektedir. $\mathrm{Bu}$ fonksiyonda bulunan devam bilgisi sayesinde açık artırmaya etmenin katılıp katılmayacağ belirlenmektedir.

Alıcı etmenler oluşturularak açık artırma sürecinde kullanacakları fiyat bilgileri eklenmiştir. Alıcı etmenler açık artırma sürecinde tekliflerini satıcı etmene gönderecek etmenlerdir. Alıcı etmenler açık artırma sürecinde addHeapItem fonksiyonuyla belirlenmiş olan fiyat bilgilerini kullanır. Her teklifte ne kadar artış yapacağı ve en son verebileceği üst sınır burada belirlenmiştir. Verilen teklif üst sınırdan büyükse etmen açık artırma sürecinden çıkmaktadır.

Şekil 4'te alıcı etmenlerin kullandığı plan alt yapısı yer almaktadır. Bu planda alıcı etmenler kendilerinden istenen işleri yerine getirirken bu plan bilgilerini kullanmaktadırlar.

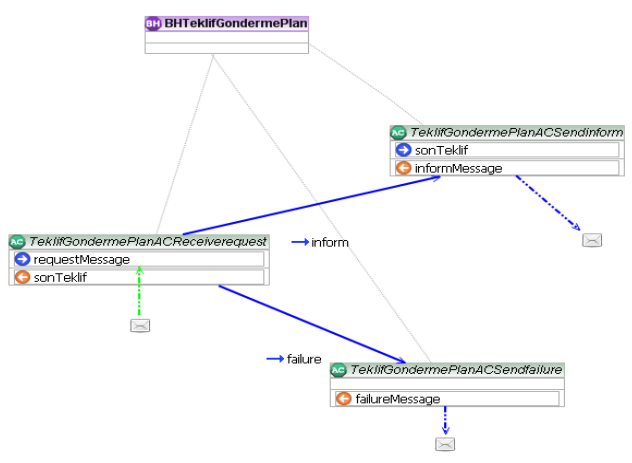

Şekil 4. Alıcı Etmenin Teklif Gönderme Planı.
Alıcı etmen için geliştirilen TeklifGönderme isimli planda yer alan TeklifGondermePlanACReceiverequest sinıfi satıc etmenden gelen fiyat bilgisini almaktadır. Bu fiyat bilgisi satıcı etmenin değerlendirmesi sonucunda alıcı etmenlere gönderilen bilgidir. Bu bilgi alıcı etmenlere geldikten sonra her etmen kendi bilgi tabanındaki sınırlamalara göre açık artırmaya katılıp katılamayacağını belirlemektedir. Satıcı etmene tekliflerini olumlu yada olumsuz olduğunu bildirmek için diğer sınıfları kullanmaktadır. $\mathrm{Bu}$ sinıflardan bir tanesi satıcı etmene alıcı etmenin teklifini ileten TeklifGondermePlanACSendinform sınıfidır. Alıcı etmen bu sınıf içerisinde kendi veri tabanına bakarak teklifini gelen fiyat üzerine ekleyerek tekrardan satıcı etmene sunmaktadır. Eğer alıcı etmen teklif vermek istemez ise o zaman TeklifGondermePlanACSendfailure sinıfi ile satıcı etmene başarısız mesajı iletilmektedir.

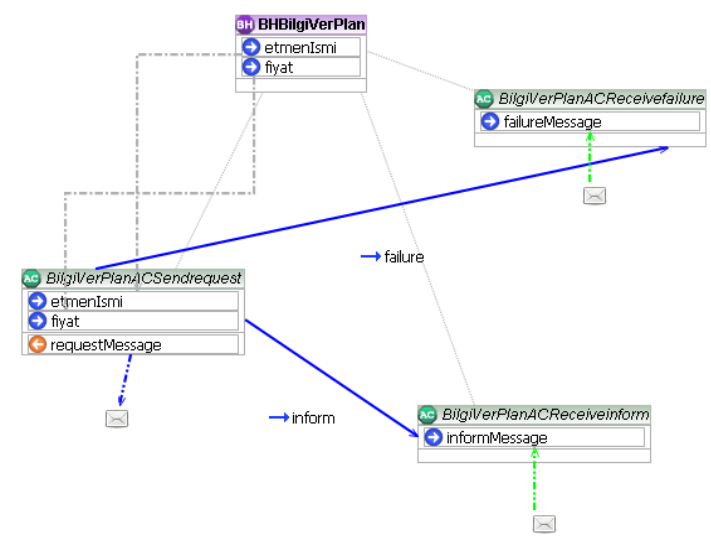

Şekil 5. Satıcı Etmenin Bilgi Verme Planı

Şekil 5'te satıcı etmenin kullandığı plan yapısı yer almaktadır. Satıcı etmen bu plan yapısını kullanarak açık artırmaya katılan etmenlerden süreç sonunda açık artırmada tek başına kalan etmenin açık artırmayı kazandığına dair bilgilendirme işlemini yapar. Satıcı etmen tarafından alıcı etmene kazandınız ya da kazanmadınız mesajı gönderilir. $\mathrm{Bu}$ plan çalıştıktan sonra açık artırma işlemi sonuçlandırılır.

Şekil 6'da alıcı etmenlerin açık artırma süreci sonunda satıcı etmen tarafindan alıcı etmene gönderilen bilgilendirme mesajının alınıp işlendiği plan yapısı görülmektedir.

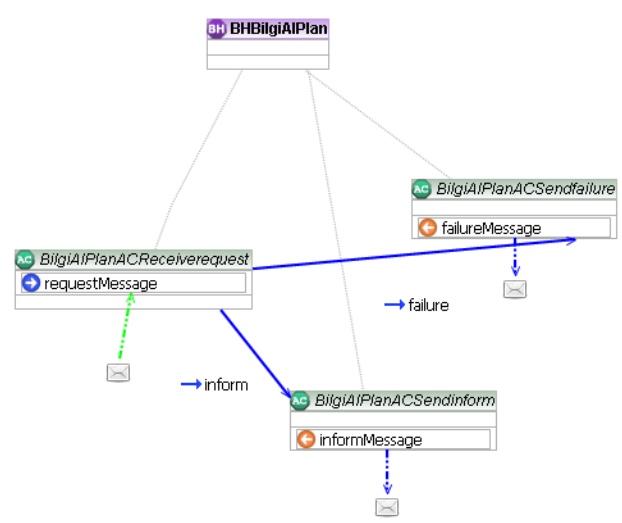

Şekil 6. Alıcı Etmenin Bilgi Alma Planı

Bu plan içerisinde satıcı etmen tarafından gönderilen mesaj bilgisi requsetMessage ile alınmaktadır ve alınan bu mesaja karşın herhangi bir olumsuzluk durumunda faiulureMesage ile cevap verilmektedir. informMessage ise alıc1 etmenin satıc1 etmene açık artırmayı kazandığını ilettiği mesajdır. 


\section{Tartışma ve Sonuç}

Bu çalışmada SEAGENT üzerinde FIPA etkileşim protokolünden biri olan FIPA İngiliz Açık Artırma Etkileşim Protokolü gerçekleştirilmiştir. Bu protokolde etmenlerin çift taraflı olarak mesajlaşmasını sağlayabilmek adına onların görevleri belirlenmiş ve bu görevler için ayrı ayrı planlar oluşturularak bu planlar içerisinde etmenlerin yapacakları işlemler gerçekleştirilmiştir.

Etmenlerin kendi veritabanlarındaki bilgileri kullanarak sonuç üretme ve bu sonuçları kullanarak da bir işi yapma ya da yapmama gibi akıllı etmenlerin sahip olduğu bir yapı şu an için yapılamamıştır. İleride yapılacak çalışmalarda etmenlerin akılcı özelliklerinin ortaya çıkarıldığı yapay zekâ algoritmalarından yararlanılarak onların daha akılcı olmaları sağlanabilir.

Etmenlerin amaçlarına ulaşabilmeleri için ortamdaki dinamik olarak değişen verileri kullanarak planlar yapması, bu planları o anki duruma göre güncellemesi ve farklı durumlar karşısında farklı tepkiler verebilmesi gerekmektedir. Örneğin borsada hisse senedi işlemleri yapan bir kişi adına çalışan etmenin kişinin belirlediği koşullar doğrultusunda bir hisse senedi satış işlemini yapması akıllı etmen sınıflandırması içerisinde adlandırılamaz. Fakat bu etmenin satış üst sınırına geldiğinde hisse senedini satmak yerine ileride bu hisse senedinin ne kadar yükselebileceği yada ne kadar düşebileceğine dair anlamsal vebdeki dinamik bilgileri toplaması ve bu bilgilerden çıkarımlar yapması ayrıca bu çıkarımlar doğrultusunda da hisse senedini satıp satmamakta kendi plan alt yapısını güncelleyip karar vermesi bizim ulaşmak istediğimiz akıllı etmenlere biraz daha yaklaşılmasına sebep olacaktır. Burada belirtildiği üzere anlamsal vebden de yararlanılarak etmenler ile ilgili çalışmalar ileride yapılabilir.

Yapılan uygulama tek bir bilgisayar üzerinde gerçekleştirilmiştir. Farklı platformlarda bulunan yazılım etmenlerinin ă üzerinde çalıştıkları bir yapı oluşturularak yazılım etmenlerinin cevap verme sürelerinin kısaltılması sağlanarak performans artırılabilir.

SEAGENT çevresi kullanılarak, FIPA'nın diğer etkileşim protokollerini gerçekleştirmek üzere çalışmalar devam etmektedir.

\section{Kaynakça}

[1] Antoniou G. ve Harmelen F. V., 2004. A Semantic Web Primer. The MIT Press., ISBN 0-262-01210-3.

[2] Daconta M.C.,Obrst L.J. ve Smith K.T., 2003. The Semantic Web: a guide to the future of XML, Web services and knowledge management, Willey Pub.
[3] Jennings N.R. ve Wooldridge M., 1998. Agent Technology: Foundations, Applications, and Markets. Springer Verlag. ISBN 3-540-63591-2.

[4] Nwana H.S., 1996. Software Agents: An overview. Knowledge Engineering Review, 11(3):1-40.

[5] Wooldridge M. ve Jennings N., 1995a. Agent Theories, Architectures, and Languages: A Survey, Intelligent Agents. Springer-Verlag, Berlin. 1-22.

[6] Harrison C. ve Cağlayan A., 1997. Agent Source Book A Complete Guide to Desktop, Internet and Intranet Agents, Wiley.

[7] Durfee E. H. ve Lesser V. R., 1989. Negotiating Task Decomposition and Allocation Using Partial Global Planning. Distributed Artificial Intelligence, 229-243.

[8] Wooldridge M., Georgeff M., Pell B., Pollack M. ve Tambe M., 1999. Intelligent Agents $V$ : Agents Theories, Architectures, and Languages. Springer Berlin Heidelberg.

[9] Genesereth M. R. ve Ketchpel S. P., 1994. Software agents. Communications of the ACM, 37 (7): 48-53.

[10] Charlton, P., \& Greenwood, D. FOUNDATION FOR INTELLIGENT PHYSICAL AGENTS.

[11] Bellifemine F., Poggi A. ve Rimassa G., 2001. Developing Multi-Agent Systems with JADE, Intelligent Agents. VII Agent Theories Architectures and Languages LNCS, 42-47.

[12] Sycara K., Paolucci M., Van Velsen, M. ve Giampapa J., 2003. The RETSINA MAS Infrastructure, Autonomous Agents and Multiagent Systems. 7(1-2): 29-48.

[13] Graham J. R., Decker K. S. ve Mersic M., 2003. Flexible Multi Agent System Architecture. Autonomous Agents and Multi- Agent Systems, 1-2.

[14] FIPA, (2003). FIPA English Auction Interaction Protocol Specification. from www.fipa.org./specs/ fipa00031.

[15] Dikenelli O., Erdur R.C., Gümüş O., Ekinci E.E., Gürcan Ö., Kardaş G., Seylan İ. ve Tiryaki M., 2005. SEAGENT: A Platform for Developing Semantic Web Based Multi Agent Systems. International Joint Conference on Autonomous Agents \& Multiagent Systems AAMAS, Utrecht the Netherlands. 1271-1272.

[16] Dikenelli O., Erdur R. C., Kardas G., Gümüs O., Seylan I., Gurcan O., Tiryaki A. M. ve Ekinci E. E., 2006. Developing Multi Agent Systems on Semantic Web Environment using SEAGENT Platform. Springer-Verlag, Vol. 3963.

[17] FIPA, (2002). FIPA RDF Content Language Specification, from http://www.fipa.org/specs/fipa00011/XC00011B.html

[18] Dikenelli O., 2009. SEAGENT Çok Etmenli Geliştirme Çerçevesi. 4. Ulusal Yazılım Mühendisliği Sempozyumu, İstanbul. 319-321.

[19] Sycara K., Williamson M. ve Decker K., 1996. Unified Information and Control Flow in Hierarchical Task Networks. AAAI-96 Workshop. 